\title{
JUVENTUD CIVILIZADA Y JUVENTUD BARBARA EN LOS MEDIOS DE COMUNICACIÓN
}

\author{
YOUTH CIVILIZED AND YOUTH BARBARA \\ IN THE MASS MEDIA
}

\begin{abstract}
JUVENTUDE CIVILIZADA E JUVENTUDE BARBARA
NOS MEIOS DE COMUNICAÇÃO
\end{abstract}

\author{
CARINA V. KaPlan \\ Virginia SAEZ
}

RESUMEN Este trabajo interpreta las representaciones sociales sobre la juventud y su trama asociada al par civilización-barbarie. El análisis del discurso se centra sobre las coberturas de situaciones de violencias en el espacio escolar de los diarios El Día, Hoy, Extra y Diagonales, de la ciudad de La Plata, Argentina, del período 1993-2011. El enfoque metodológico es cualitativo y la interpretación de los datos se llevó a cabo mediante el análisis socioeducativo del discurso. Esta investigación amplía la base empírica con la que pensar y discutir las representaciones sobre los jóvenes en los medios de comunicación.

Palabras Claves: Juventud. Civilización. Medios de comunicación.

Abstract This work interprets the social representations about the youth and its frame associated with the pair civilization-barbarism. The analysis of the discourse focuses on the coverage of situations of violence in the school space of the newspapers of the day, today, Extra and diagonals, of the city of La Plata, Argentina, in the period 1993-2011. The methodological approach is qualitative, and the interpretation of the data is carried out through the analysis of socio-educational discourse. This research extends the empirical basis with which to think about and discuss the representations on young people in the media.

Keywords: Youth. Civilization. Media.

REsumo Este trabalho interpreta as representações sociais sobre a juventude e sua trama associada ao par civilização-barbárie. A análise do discurso centra-se na cobertura de situações de violência no espaço escolar dos jornais El Día, Hoy, Extra e Diagonales, da cidade de La Plata, Argentina, publicados no período entre 1993-2011. O enfoque metodológico 
é qualitativo e a interpretação dos dados foi realizada através da análise socioeducativa do discurso. Esta pesquisa amplia a base empírica com a qual pensar e discutir representações sobre jovens nos meios de comunicação.

Palavras chave: Juventude. Civilização. Meios de Comunicação.

\section{INTRODUCCIÓN}

Los medios de comunicación ocupan posiciones estratégicas en la disputa por los sentidos, en tanto producen, reproducen, legitiman y deslegitiman representaciones y prácticas sociales. A partir de los años noventa del siglo pasado, se observa cómo los medios construyen el estereotipo de un sujeto peligroso mediante procesos de selección noticiosa y estrategias discursivas, que operan como mecanismos de control social (DELGADO, 1998; ALBA, 2002; VASILACHIS DE GIALDINO, 2004 y SAINTOUT, 2013).

En este contexto, nos preguntamos acerca de cómo la prensa escrita participa de un tipo de sensibilización sobre cierta configuración emotiva referida a los fenómenos de las violencias en la escuela. A través de sus prácticas discursivas, los medios explican, ordenan y califican los acontecimientos y escenas de la vida escolar tendiendo a visibilizar sus falencias (IGLESIAS, 2015; SAEZ, 2015) y de forma difusa y contradictoria (NÚÑEZ, 1999).

Los medios crean y recrean una forma de sensibilidad específica frente a la problemática de la violencia (KAPLAN, 2011), saturando a través de imágenes que incluyen a los jóvenes en hechos de violencia, imponiendo con evidencia creciente en la opinión pública la sensación de una escuela atravesada por la violencia (MÍGUEZ Y NOEL, 2006; UNICEF Y FLACSO, 2011). Cabe destacar que la violencia es un valor; noticia determinante en las agendas periodísticas latinoamericanas (CONSEJO NACIONAL DE TELEVISIÓN DE CHILE, 2002; HERRERA, 1998; LÓPEZ Y CERDA, 2001; COMFER, 2005). La violencia está presente en la mayoría de los programas y en la mayor parte de la franja de programación. La visibilización reiterada de estos sucesos puede contribuir a crear un clima de aceptación de la violencia.

Los aportes de la sociología figuracional de Elias (2009) resultan fértiles para la indagación del este fenómeno, en tanto nos permite pensarlo desde una perspectiva socio-histórica y procesual, entendiendo a su vez, que las prácticas discursivas de los medios hunden sus significaciones en la cultura. La recepción, los usos y las apropiaciones de la obra de Norbert Elias se han ampliado en el campo de la Educación a partir de investigaciones con perspectiva relacional que abordan temáticas como violencia, infancia, civilidad, habitus, diversidad, inclusión, entre otras (KAPLAN Y ORCE, 2009; KAPLAN Y SARAT, 2014 y 2016).

Así, este artículo propone un análisis sobre la presentación de la juventud en el discurso mediático, en diálogo con las teorías de Norbert Elias, en la intersección entre el campo de la educación y la comunicación en Argentina. Es preciso tener en cuenta que su obra ha sido marginal en el tratamiento de las ciencias sociales en los países latinoamericanos. 


\section{Aspectos metodológicos}

El análisis que se presenta forma parte de un estudio más amplio que tuvo como objetivo general caracterizar y analizar las prácticas discursivas (textuales e icónicas) del fenómeno de las violencias en las escuelas en los diarios El Día, Hoy, Extra y Diagonales, de la ciudad de La Plata, en el período 1993-2011.

Dadas las características del objeto de estudio el abordaje metodológico fue cualitativo, asumiendo la indagación un carácter exploratorio. No se planteó contrastar y validar las hipótesis presentadas, sino realizar un análisis de las mismas con base en los datos empíricos (SIRVENT, 2003). La metodología cualitativa es consistente con el interés de nuestro trabajo por acceder a una comprensión del fenómeno de estudio que nos permita sumar conocimiento interpretativo y elaborar hipótesis sustantivas.

El estudio fue sincrónico, pues se hizo un corte transversal en el tiempo, estudiando qué situaciones se tipifican como violencias en las escuelas, y el tratamiento de las taxonomías en los distintos diarios seleccionados, con intención de estudiar las coberturas mediáticas.

Se delimitaron como unidades de análisis los discursos sobre las violencias en los espacios escolares en las versiones digitales e impresas de los diarios El Día, Hoy, Extra y Diagonales, de la ciudad de La Plata, en el período 1993-2011.

El corpus se conforma por tres mil quinientas ochenta y una notas: dos mil ochenta del diario El Día, mil sesenta y tres del diario Hoy, trescientas treinta y seis del diario Extra y ciento dos del diario Diagonales.

Respecto al trabajo de campo, en una primera etapa se realizó el relevamiento de las notas de los cuatro diarios mencionados. La búsqueda se realizó en función de los titulares, de los epígrafes y del cuerpo de la nota. Las palabras utilizadas como motor de búsqueda fueron las siguientes: "violencia escolar", "violencia juvenil", "agresión", "violencia juvenil y escuela", "violencia", "vandalismo escolar", "violencia hacia el edificio escolar", entre otras.

La etapa de procesamiento de la información se realizó en el marco del análisis socioeducativo del discurso (MARTÍN CRIADO, 2014). En un primer momento se examinó el nivel morfológico y el nivel compositivo de las fotografías sin limitarse a una interpretación inmanente sino que se analizó la concepción socioeducativa que se expresa a través de estos niveles, conformando un estudio global. Como sostiene Amalia Barbosa Martínez, "el método documental no solamente supone la superación de un análisis formal e inmanente, sino también la superación de una análisis autónomo" (2006, p. 400).

\section{LOS JÓVENES EN LOS MEDIOS DE COMUNICACIÓN}

El periodismo cuenta con una posición privilegiada en la producción de discursos sociales, dado que dispone de los medios más potentes para hacerlos circular e imponerlos (BOURDIEU, 2002). Las noticias periodísticas, en tanto construcciones de la realidad (VERÓN, 1983), producen y reproducen principios de visión y división del mundo social. 
Los modos por los cuales la prensa construye la representación de la escuela asociada a la crisis social y a la violencia como parte de una agenda mediática generan efectos que reproducen discursos e imágenes sobre la escuela y los sujetos que la habitan (BOURDIEU Y WACQUANT, 2005). Los medios de comunicación, como productores de discursos, son portadores de un capital simbólico acumulado que es el que sostiene y legitima el ejercicio del poder simbólico (BOURDIEU, 1988). A través de estrategias discursivas, históricamente construidas, se construyen ciertas representaciones de lo social como verosímiles (MARTINI, 2004; ZULLO, 2002). Como actor político (BORRAT, 1989; QUÉS, 2013), los medios permiten la visibilidad de los acontecimientos, pero los producen favoreciendo la imagen de verdad sustentada por un determinado grupo de opinión. El campo periodístico somete los acontecimientos a un trabajo de construcción según sus intereses, y se constituye en un barómetro de ese hecho (CHAMPAGNE, 1999). En tanto mediadores del mundo, la carga contenida en ese significado social y en las modalidades discursivas con las que apelan al público, hacen de las noticias un agente fundamental de la normalización o naturalización del sentido común (MARTINI, 2007).

Desde sus orígenes, la prensa fue un lugar donde se generaron sentidos sobre la escuela, sin embargo, carecemos de estudios que den cuenta cómo se representa el ámbito educativo en la opinión pública. A partir de la fundación del Sistema de Instrucción Pública Centralizado Estatal (PUIGGROS, 2006), los medios de comunicación constituyeron un ámbito donde se pensó, se organizó, se discutió, y se propuso acciones educativas (FINOCCHIO, 2009).

Desde el programa de investigación dirigido por la Dra. Kaplan se han realizado aproximaciones sucesivas para la comprensión de una serie de componentes sobre los discursos que construyen los medios acerca de las escuelas (KAPLAN, 2012). Los discursos de los medios de comunicación colaboran a crear una representación de una escuela en crisis. Se trata de discursos que circulan por dentro y por fuera de la escuela (LAHIRE, 1999; FINOCCHIO, 2009; SAEZ, 2016). Lo que se piensa y se dice públicamente sobre la educación no sólo connota las miradas de quienes la observan y comentan sobre ella sino que, convertido en el sentido común pedagógico de directivos, docentes, padres y estudiantes, también atraviesa las decisiones cotidianas del mundo escolar. La circulación de la información puede también contribuir a despolitizar lo social y des-socializar lo político (LANDI, 1984).

Hay un conjunto de estudios sociohistóricos que indagan el proceso por medio del cual los sectores juveniles adquirieron mayor presencia en la prensa nacional desde 1970 (TOSSOUNIAN, 2013; AGOSTINI, 2013; KEJNER, 2011). En las décadas posteriores a la Segunda Guerra Mundial se produjo un proceso generalizado y sin precedentes de visibilización de los y las jóvenes. Las investigaciones (CARNOVALE, 2011; FEIXA, 1998; CASAL et al., 2006; LEVI Y SCHMITT, 1996) consideran que los sentidos construidos acerca de las juventudes se articulan en torno a dos imágenes generales: la esperanza y el temor. Por un lado, la "buena juventud", estudiosa, trabajadora, respetuosa de las instituciones. Por otro lado, una juventud subversiva y desviada, que falla a lo que la sociedad espera de ella, ya sea porque se niega a insertarse en el trabajo o el estudio, porque su apariencia 
no respeta las pautas tradicionales o porque se involucra en la protesta social y política por fuera de las instituciones. En continuidad con esta diferenciación, Robert Muchembled (2010) analiza el comportamiento agresivo en la Europa Occidental del siglo XIII hasta la actualidad y describe como el joven tipificado como delincuente es individualizado por su contraste con el joven normal.

La clásica investigación de Elias y Scotson sobre las relaciones entre "los establecidos y los forasteros", comentada por Elias (2003), suministra elementos de juicio para situar la violencia en un microcosmos social donde se observa que "la capacidad de un grupo de apuntalar la inferioridad humana del otro grupo y de hacerla valer era una función de una figuración específica que ambos grupos formaban entre sí" (ELIAS, 2003, p. 224). Los que pertenecen ven a los otros como "incivilizados", "violentos", "bárbaros", incluso infrahumanos.

Es necesario tener en cuenta que estas divisiones entre los de adentro del grupo y los de afuera del grupo son una característica universal de toda formación de grupos humanos; una característica que la especie humana comparte con especies sociales como los primates (SWAAN, 2011). La división entre un nosotros - incluidos - que se sienten superiores y un ellos - excluidos - que se perciben como inferiores no es nueva. A lo largo de la historia de las sociedades occidentales a los sujetos en situación subalterna se los ha tipificado como "bárbaros" y "salvajes" en contraposición a los "civilizados". Como sostiene Kaplan (2016), la sociedad europea occidental llevó a cabo sus guerras coloniales y expansivas en nombre de la cruz durante la Edad Media, como más tarde lo haría en nombre de la civilización.

En este artículo presentamos cómo estas dos representaciones preeminentes sobre las juventudes, en correlato con proyecto pedagógico hegemónico civilizatorio-estatal, toman sentido en el discurso mediático a través de dos recurrencias: la imagen de ciertos estudiantes como vándalos que alteran el orden escolar y la descripción de estos jóvenes desde una dimensión cognitiva como irracionales y bárbaros. En contraposición a otro modelo de juventud civilizada, con buenas costumbres, conectados con la cultura letrada.

Se ha trabajado con las formas de designar, nominar, adjetivar al joven violento-joven no violento / alumno violento-alumno no violento. En todos los casos se interpretó a partir de las categorías formuladas por las propias coberturas. Desde la perspectiva de esta investigación, estos términos son adjetivaciones o atribuciones con un contenido expreso y uno implícito, es decir, con una matriz de significación oculta (KAPLAN, 2008).

Con la imagen de vándalos atacando escuelas, se van configurando y visibilizando los personajes, donde predomina la cadena de sentido de joven-vándalo-salvaje. Proponiendo la representación de una barbarie que ataca la escuela, la atribución del término "vándalo" no parece ser inocente, dado que asigna una mirada sobre el otro peyorativa. Esto nos lleva a pensar cómo en el discurso mediático, a través de este tipo de nombramientos sobre los jóvenes, se refuerza y abona al par civilización-barbarie presente en la historia de los sistemas educativos. Observemos algunas evidencias:

"Ringuelet, destacan en una nota: 'En los últimos tiempos nuestra escuela ha sido objeto de actos de barbarie, realizados por desconocidos, generalmente en horas de la noche, que incluyen destrozos en la dirección, en los pupitres y 
bancos de las aulas, en las láminas realizadas por los alumnos, en la biblioteca, robo de aparato telefónico, salones sucios por las necesidades fisiológicas de los delincuentes, corte de la cuerda del mástil, etc. Creemos innecesario el comentario sobre lo deplorable de este tipo de actos que son la muestra de una sociedad enferma y en crisis"” (EL DÍA, 08-04-1993).

"Ahora, me pregunto: ¿cómo hallar respuestas a situaciones tan concretas y prioritarias, como este caso, hallándose en un final de siglo donde los valores se encuentran invertidos, donde la insensibilidad es normal, la corrupción perfectamente disfrazada y la violencia, según los parámetros modernos, surgiendo como un singo enaltecedor, cuando para una persona normal y equilibrada significaría un franco retroceso a épocas primitivas?” (EL DÍA, 18-03-1993).

“La 'invasión' india a una escuela" (EL DÍA, 04-10-1994).

"Un acto bárbaro y despreciable" (HOY, 04-09-2004).

“Aterrado. Fue víctima de la barbarie terrorista, en Rusia” (HOY, 04-09-2004).

Esto se vincula con la relación individuo-sociedad que menciona Norbert Elias: "conceptos como 'individuo' y 'sociedad' no se remiten a dos objetos con existencia separada, sino a aspectos distintos, pero inseparables, de los mismo seres humanos" (2009, p. 37). Desde esta perspectiva, la violencia expresa o emerge en determinadas configuraciones de las relaciones de los actores de la vida escolar, habida cuenta de los estados de equilibrio de poder y de las interdependencias. La "barbarie" surge de una matriz social particular.

Esta atribución de sentido que se realiza al nombrar a determinados jóvenes como "vándalos" permite pensar cómo se apela a un imaginario sobre la escuela civilizadora amenazada por la barbarie de salvajes. A continuación presentamos un enunciado que permite identificar esto:

"En algún momento de la historia de nuestra sociedad nacional se interrumpe el proceso civilizador de la educación, se obliga a una escolarización que las familias no demandan, que los niños y adolescentes no desean o no valoran, por no encontrar en ella un proyecto de futuro, y en algunos casos casi imposibles de proyectar, por no haber recibido en los primeros años de vida las herramientas necesarias" (EL DÍA, 24-11-2011).

La imagen de vándalos atacando escuelas va configurando y visibilizando a personajes claves, e instaura la cadena de sentido de joven-vándalo-salvaje, lo que contribuye a reducir la problemática a la "maldad y crueldad" de determinadas personas. Veamos los siguientes casos:

"De acuerdo a versiones que circulaban ayer, se conocería la identidad de las personas que, según se dijo, 'por maldad han atacado la escuela' pero nadie se atrevió hasta el momento de efectuar la denuncia correspondiente" (HOY, 20-04-1995).

"Los sujetos habrían llegado con el único propósito de hacer daño y por eso llevaron los elementos necesarios para desatar el incendio. Pese a las pérdidas sufridas, todos coincidían ayer en señalar que 'tuvieron suerte', pues de haber ocurrido algunas horas antes, la escuela habría quedado devastada por el fuego" (HOY, 06-08-2005). 
Así pues, es interesante recuperar la contribución de Norbert Elias sobre la individualidad como determinada por la estructura de la sociedad en la que se nace, lo cual hace que existan variaciones en las formas de individuación de un grupo social a otro, e inclusive al interior de un mismo grupo, y de una época a otra. Esto pone en tensión la mirada simplificada de estas prácticas discursivas mediáticas, dado que la individualidad que alcanzará una persona no depende de su constitución, sino de todo un proceso de individuación, donde las relaciones sociales juegan un papel central. Las configuraciones sociales y los entrelazamientos van definiendo a las prácticas sociales de individuos concretos. En este sentido también:

\begin{abstract}
La agresividad se ve hoy restringida y sujeta, gracias a una serie considerable de reglas y de convicciones que han acabado por convertirse en autocoacciones. La agresividad se ha transformado, "refinado", "civilizado", como todas las demás formas de placer y únicamente se manifiesta algo de su fuerza inmediata e irreprimible bien sea en los sueños bien en explosiones aisladas que solemos tratar como manifestaciones patológicas (ELIAS, 2009, p. 283).
\end{abstract}

\title{
LA BARBARIE COMO DIMENSIÓN IDENTITARIA EN LA TIPIFICACIÓN DEL ALUMNO VIOLENTO
}

Otra relación que emerge de las coberturas es la designación de los actos de ciertos jóvenes como "irracionales". Se alude a la falta de discernimiento moral e incapacidad para distinguir entre aquello que está bien y aquello que no. Sus manifestaciones violentas son producto de "un acto irracional" (HOY, 07-09-2005).

En el corpus analizado se registran representaciones de la alteridad groseras (WIEVIORKA, 2009), desprovistas de sutileza, ligadas a una lógica de la diferenciación:

“Cada vez más jóvenes se eonvierten en monstruos” (EL DÍA, 09-04-1994).

Estas nominaciones marcan una preocupación por controlar los jóvenes, reducirlos a una fuerza social prácticamente animal, en todo caso muy inferiorizada, cuyos riesgos de revuelta o de cólera y de rabia exigen una gran vigilancia.

En la representación de las violencias entre estudiantes se hace una atribución de sentido que asocia al joven violento-alumno violento con la irracionalidad de una barbarie que ataca al espacio escolar a través de actos de vandalismo y de violencia hacia los actores de la comunidad educativa. A continuación se muestran algunos ejemplos:

"Estados Unidos calificó la toma de la escuela en Beslán, Rusia, por presuntos separatistas chechenos como un acto 'bárbaro' y 'despreciable', y responsabilizó a los 'terroristas' de las muertes ocurridas. 'No hay justificación racional para tomar una vida inocente, y la naturaleza bárbara de este acto terrorista es despreciable', dijo el vocero de la Casa Blanca, Scott McClellan, en Moosic, 
antes de que el presidente, George W. Bush, diese un discurso en esa ciudad de Pensilvania. 'La responsabilidad por la trágica pérdida de vidas recae sobre los terroristas. Estados Unidos está lado a lado con Rusia en nuestra lucha mundial contra el terrorismo"' (HOY, 04-09-2004).

"Los escolares británicos volvieron a ser blanco de la irracionalidad de jóvenes desmedidos" (HOY, 09-07-1996).

"A las 14:05 una maestra de segundo grado me comunicó que dos de los chicos habían ingresado al patio, luego de saltar un paredón, e intentaban bajarle los pantalones al alumno" (HOY, 17-11-1995).

"De un momento a otro la paz educativa se alteró radicalmente: cientos de chicos corrían de un lado al otro del patio para impedir que los encapuchados les pegaran un tomatazo o un huevazo. Docentes y preceptores inútilmente intentaban mantener la calma y protegerse frente a la irracional agresión" (HOY, 17-07-1999).

Desde una caracterización brutal se asocia cierto sector de los estudiantes a la barbarie y se identifica al joven violento-alumno violento como objeto de la intervención de la escuela, a pesar de que haya perdido su eficacia por la crisis educativa. La propuesta es civilizar la barbarie en este espacio educativo, interpretando la escolarización de los jóvenes como un lugar para el disciplinamiento social mediante la vigilancia y el encauzamiento de su conducta. Veamos cómo aparece en las notas:

“¿Qué pasó para que no sea el tránsito obligatorio, para que generaciones de jóvenes encuentren en ella el cauce indicado a sus ansiedades de adolescentes y una realidad que les permita acceder a una capacitación apta para el campo laboral, que además sea marco referencial a sus experiencias de vida, entre las que incluyen la constitución de su familia, el trabajo para sostenerla, y el estudio para proyectarla?" (HOY, 08-07-1994).

"La escuela es la que debe inculcar en estos jóvenes las buenas costumbres" (EL DÍA, 06-04-1993).

"Simplifican este grave problema apuntando contra los adolescentes. Ya no se invierte en la civilización de las nuevas generaciones: falta presupuesto educativo" (EL DÍA, 18-08-1993).

"La educación de la juventud, una tarea que debe mancomunar la escuela para una sociedad civilizada" (EL DÍA, 17-04-1993).

"Se afirma que la suerte de la civilización y, por ende, de la educación depende más de la tabla de valores propuesta que del progreso técnico acumulado, y que es en ese punto en el que se debe hincar y golpear para mover voluntades y encontrar, con seguridad, los objetivos, funciones y metodologías más significativas y trascendentes para la transformación del proceso. Ante la realidad declarada y asumida de que la insólita crisis general que nos flagela y esclaviza tiene su razón y fundamento en la profunda crisis moral educativa, producida por la subversión de sus valores, la que nos conduce, insensiblemente, con la consecuente crisis del amor, de la solidaridad y de la ética, a la crisis de la civilización" (EL DÍA, 24-06-1994).

En las notas periodísticas se apela al espacio escolar como un lugar de transformación de la juventud bárbara a la juventud civilizada, por medio de la inculcación de las buenas 
costumbres, el encausamiento de las ansiedades generacionales y la instalación en el orden de la cultura por su conexión con la cultura letrada.

El joven violento-alumno violento queda asociado a la barbarie primitiva que se mantiene en el orden de la naturaleza. Estas miradas sobre los estudiantes tienen raigambres históricas y reflejan las luchas en las relaciones intergeneracionales (BOURDIEU, 1991). Ya las posiciones pedagógicas de Sarmiento de principios del siglo XX suponen la implantación de un sistema de instrucción pública pensado como dispositivo para alterar la continuidad de las generaciones, como un medio para cambiar su moralidad y sus hábitos (PUIGGRÓS, 2006; CARLI, 2012). En el caso argentino, como analizan Krotsch y Gebara (2016), la civilización sintetizó "tensiones y contradicciones y será a través de la educación y ella, a través de la escuela moderna, uno de los instrumentos ideales para cumplimentar dicha tarea" (p. 62).

A su vez, tiene un correlato con los aportes de la sociología figuracional de Norbert Elias, quien define la violencia y la civilización como formas específicas de interdependencias en tanto procesos complementarios. En su estudio sobre la cultura occidental del siglo XVI y la Edad Media evidencia cómo la civilización dependerá del nivel de control de la violencia, del monopolio de los impuestos que permiten constituir una fuerza suficientemente efectiva para imponer la pacificación interna, entre otros aspectos. En la figuración francesa del siglo XVII, Elias analiza la civilización como producto del desarrollo y con intención de expandirse a otros pueblos que se le oponían por su opuesto: la barbarie. La civilización es pensada no como un estado fijo sino como un proceso donde participan la educación y el refinamiento de las costumbres, para diferenciarse de lo bárbaro y no civilizado.

Ahora bien, también aparece en las notas la "importación" de términos desde la perspectiva judicial o policial, como la de "menor" para nombrar a los jóvenes que protagonizan las noticias del fenómeno. Desde el ámbito del que proviene este término, refiere a la persona que no alcanzó la mayoría de edad, y designa especialmente a aquellos acusados de cometer un delito. Por tal motivo, su uso en el discurso social conlleva un significado peyorativo, que termina reforzando prejuicios, estigmas y desigualdades sociales. Este nombramiento opera diferenciando entre dos supuestos modelos de infancia y juventud: los niños o jóvenes y los menores. Asimismo, las intromisiones de la terminología judicial están ligadas a las soluciones propuestas en las noticias sobre las violencias en el espacio escolar.

A partir de su estatus jurídico, la aplicación de este término a los jóvenes refiere a dos sentidos: menores de edad y menores de razón frente al adulto. Desde los orígenes del sistema escolar argentino hay una asociación entre la identidad jurídica y la identidad educativa. En el discurso sarmientino esta asociación permitió construir la autoridad del maestro, establecer una frontera de edad asentada en lo que establecía el código civil para sostener el poder sobre los estudiantes, sin derechos propios y subordinados a la autoridad de los adultos. La minoría de razón de los jóvenes los convierte en seres incompletos, por estar en situación de crecimiento o de exceso de pasión (CARLI, 2012). 


\section{Consideraciones finales}

Desde un estudio socioeducativo de la prensa argentina se mostró como los medios crean y recrean una forma de sensibilidad específica frente a las problemáticas de la educación secundaria y hacien blanco de la responsabilidad a ciertos jóvenes que son tipificados como bárbaros y amenazantes.

Partimos del supuesto de que hay una interrelación entre las percepciones acerca de las violencias y los umbrales de sensibilidad, donde los medios ocupan un rol central en dicha construcción. Los nombres de las cosas sociales son objeto de una lucha simbólica; de allí que es necesario examinar el proceso de constitución y legitimación de ciertas formas de clasificación que operan en el mundo social. La información periodística constituye una fuente privilegiada para el análisis de las configuraciones emotivas en determinado tiempo histórico y social.

En las coberturas estudiadas, los sentidos se construyen desviando la discusión de los problemas estructurales, resumiendo las violencias en el espacio escolar y simplificando la cuestión con el antagonismo civilización-barbarie. En las prácticas discursivas se construyen una imagen de un "nosotros", adjudicándose un mayor valor social o superior, mientras que a través de la caracterización de la barbarie se ponen en juego una serie de categorías estigmatizantes, ya disponibles en el entramado social, con las que catalogan a ciertos jóvenes como de menor valor social. Estas oposiciones tienen eficacia ideológica porque remiten a oposiciones fundamentales del orden social, entre dominantes y dominados.

Todos los agentes de una formación social determinada tienen en común, efectivamente, un conjunto de esquemas de percepción fundamentales, que reciben en un comienzo de objetivación en las parejas de adjetivos antagónicos comúnmente empleados para clasificar y calificar a las personas o los objetos en los campos más diferentes de la práctica.

\footnotetext{
Matriz de todos los lugares comunes, que si se imponen tan fácilmente es porque tienen a su favor todo el orden social, la red de oposiciones (...), [que] tiene como principio la oposición entre la "elite" de los dominantes y la "masa" de los dominados, multiplicidad contingente y desordenada, intercambiable e innumerable, débil y desarmada, sin otra existencia que para la estadística (BOURDIEU, 1991, p. 479).
}

En las notas analizadas aparecen juicios de descalificación hacia un sector de la juventud. A través de los actos de clasificación, como la atribución del término "vándalo" a determinados estudiantes, se presenta una mirada de sospecha sobre cierto sector de la juventud como responsables de la inseguridad y de la violencia en el ámbito escolar, apelando a un imaginario sobre la escuela civilizadora amenazada por la barbarie de los salvajes.

El lenguaje penal utilizado cataloga a los estudiantes, sobre todo a aquellos atravesados por las condiciones materiales y simbólicas de la desigualdad social, como delincuentes, matones, menores. Esto nos lleva a pensar cómo el discurso mediático, mediante este tipo de nombramientos hacia ciertos jóvenes, refuerza y abona al par civilización-barbarie, 
tan presente en la historia de los sistemas educativos. Las representaciones de los discursos mediáticos sobre los jóvenes aluden predominantemente a caracterizaciones del plano intelectual y del ámbito cognitivo-académico, como la racionalidad de sus actos, para definirlos como una juventud civilizada o una juventud bárbara.

Esto sucede en una temporalidad educativa donde se amplía la escolarización obligatoria al nivel secundario. ${ }^{1}$ En nuestros contextos latinoamericanos de ampliación de derechos, los grupos consolidados del sistema educacional tienden a rechazar el ingreso o la permanencia de los recién llegados con múltiples orígenes sociales, con su memoria social, con sus propios valores culturales y que suelen ser adjetivados como "bárbaros", "incivilizados", "mal educados".

Los medios de comunicación reproducen y transmiten el racismo, perpetuando estereotipos y prejuicios y ejerciendo efectos específicos en la formación del racismo (VAN DIJK, 2007). Los temas, la selección del léxico, la retórica utilizada y la argumentación contribuyen sistemáticamente a ofrecer una imagen sesgada que favorece la polarización elitista, profunda e ideológicamente edificada, entre un "nosotros" y un "ellos". Así, analizamos algunas operaciones mediáticas que entran en complicidad con la asociación de comportamientos o ciertos atributos negativos con determinado grupo y la yuxtaposición de la información de un grupo determinado con la de un problema social (como la de la violencia).

En este escrito se ha evidenciado como la sociología posibilita la interpretación de los fenómenos sociales y educativos, de nuestras sociedades modernas y globalizadas, en las que los individuos están cada vez más interdependientes en redes complejas, donde los medios de comunicación ocupan un lugar central en la producción y reproducción del discurso social (POOLI, 2009). Sin embargo, es necesario evitar la imagen de relaciones en sentido único y determinante de los medios de comunicación. Muchos actores intervienen en la producción de las noticias y en las representaciones:

\begin{abstract}
Como hay tan poca homogeneidad y unilateralidad sobre el impacto directo que pueden producir los medios en materia de racismo, las influencias que ejercen tampoco son uniformes y existe una amplia diversidad de intereses y puntos de vista, individuales y colectivos, políticos y privados, que pesan en la producción mediática (WIEVIORKA, 2009, p. 157).
\end{abstract}

Los medios de comunicación son abordados como vectores del racismo en tanto sus representaciones de la alteridad y el tratamiento de las diferencias. Retomamos de Wieviorka los tres modos que postula de reconocimiento del racismo en la representación de la alteridad.

De esta forma, este trabajo realiza una contribución específica a la reconstrucción de los sentidos del discurso mediático referido a la juventud. Las prácticas discursivas que

En 1993, en la Ley Federal de Educación se extendió la obligatoriedad a octavo y noveno año, y en 2006, en la Ley de Educación Nacional se establece la escuela secundaria obligatoria. Estos aspectos son relevantes en la lucha simbólica por la representación de la escuela y los jóvenes. 
enuncian refuerzan una serie de creencias sociales que configuran un sentido práctico de la doxa. A través de ciertos procedimientos, como la metáfora de la barbarie se presenta a los jóvenes de sectores socialmente desfavorecidos, como la cara de la inseguridad y de la violencia en el espacio escolar. La mirada de sospecha sobre los alumnos contribuye a la estigmatización en lugar de dar una respuesta educativa a favor de la inclusión, sobre todo si tenemos en cuenta que en contextos societales de desigualdad la tipificación de "pobre" está casi mecánicamente asociada en la creencia social penalizante (el sentido común o doxa criminalizante) a la de "delincuente" (KAPLAN, 2011).

\section{REFERENCIAS}

AGOSTINI, Belén. La(s) juventud(es) como producto social e histórico. Representaciones en el diario La Nación durante los sesenta. En: X Jornadas de Sociología. Facultad de Ciencias Sociales, Universidad de Buenos Aires, Buenos Aires, 2013.

ALBA, Gabriel. Los niños en la prensa colombiana del crimen. En: Signo y Pensamiento, v. 21, n. 41, p. 107-119, 2002.

BARBOSA MARTÍNEZ, Amalia. Sobre el método de la interpretación documental y el uso de las imágenes en la sociología: Karl Mannheim, Aby Warburg y Pierre Bourdieu. En: Sociedade e Estado, 21(2), p. 391-414, 2006.

BORRAT, Héctor. El periódico, actor político. Barcelona: Gustavo Gili, 1989.

BOURDIEU, Pierre. Cuestión de Palabras. Una visión más modesta del rol de los periodistas. En: O. Kulesz (Trad.). Pensamiento y acción, p. 61-66, 2002.

BOURDIEU, Pierre. Espacio social y poder simbóico. En: Cosas dichas. Buenos Aires: Gedisa, p. 46-51, 1988.

BOURDIEU, Pierre. La distinción. Criterio y bases sociales del gusto. Madrid: Taurus Humanidades, 1991.

BOURDIEU, Pierre y WACQUANT, Louis. El propósito de la sociología reflexiva. En: Una invitación a la sociología reflexiva. Buenos Aires: Siglo XXI, 2005.

CARLI, Sandra. Niñez, pedagogía y política. Transformaciones de los discursos acerca de la infancia en la historia de la educación argentina 1880-1955. Buenos Aires: Miño y Dávila, 2012.

CARNOVALE, Vera. La generación del sesenta. Rebeldía, protesta y revolución. En: Curso Juventudes en América Latina y Argentina. Cultura, política e identidades del siglo XX al XXI. Buenos Aires: CAICYT CONICET, 2011.

CASAL, Joaquín, GARCÍA, Maribel, MERINO, Raquel, QUESADA, Miguel. Aportaciones teóricas y metodológicas a la sociología de la juventud desde la perspectiva de la transición. En: Papers, v. 79, n. 1, p. 21-48, 2006. 
CHAMPAGNE, Patrick. La visión mediática. En: Pierre Bourdieu La miseria del mundo. Buenos Aires: Fondo de Cultura Económica, p. 51-63, 1999.

COMITÉ FEDERAL DE RADIODIFUSIÓN (Comfer). Índice de violencia de la televisión argentina. Buenos Aires. Disponible en: <www.comfer.gov.ar>. 2005.

CONSEJO NACIONAL DE TELEVISIÓN DE CHILE. Barómetro de violencia $\mathbf{N}^{\mathbf{2}} \mathbf{2 :}$ Noticieros 2002. Santiago de Chile: Consejo Nacional de Televisión de Chile. Disponible en: <www.cntv.cl/link.cgi/Publicaciones/2002>. 2002.

DELGADO, Francisco Javier. Comunicación, inseguridad ciudadana y control social. Comunicación. Estudios Venezolanos de Comunicación, 103 (1), ago., 1998.

ELIAS, Norbert. El proceso de la civilización. México: Fondo de Cultura Económica, 2009.

ELIAS, Norbert y SCOTSON, John L. Ensayo acerca de las relaciones entre establecidos y forasteros. En: Revista española de investigaciones sociológicas, n. 104, p. 219-251. Madrid: Centro de Investigaciones Sociológicas Madrid, 2003.

FEIXA, Carles. De jóvenes, bandas y tribus. Antropología de la juventud. Barcelona, España: Ariel, 1998.

FINOCCHIO, Silvia. La escuela en la historia argentina. Buenos Aires: Edhasa. Goffman, 2009.

HERRERA, Antonio. Influencia de la guerra civil en El Salvador en el desarrollo de la prensa nacional (1980-1992). En: Revista Latina de Comunicación Social 1, 1998.

IGLESIAS, Andrea. ¿Todo tiempo pasado fue mejor? Un análisis de la formación y el desempeño de los nuevos docentes y sus representaciones en la prensa gráfica argentina (2000-2013). En: Revista mexicana de investigación educativa, n. 20, v. 64, p. 123-151, 2015.

KAPLAN, Carina Viviana. El racismo de la violencia. Aportes desde la sociología figuracional. En: Kaplan, C. V. y Sarat, M. (Comp.) (2016). Educación y procesos de civilización. Miradas desde la obra de Norbert Elias. Editorial de la Facultad de filosofía y Letras. Universidad de Buenos Aires. Buenos Aires, Argentina, 2016.

KAPLAN, Carina Viviana. Jóvenes en turbulencia. Miradas críticas contra la criminalización de los estudiantes. En: Propuesta Educativa, v. 20, n. 35, p. 95-103, 2011.

KAPLAN, Carina Viviana. "Mirada social, exclusión simbólica y auto-estigmatización". En: Carina Kaplan, Lucas Krotsch y Victoria Orce, Con ojos de joven. Relaciones entre desigualdad, violencia y condición juvenil. Buenos Aires: Editorial de la Facultad de Filosofía y Letras, UBA, 2012.

KAPLAN, Carina Viviana. Talentos, dones e inteligencias. El fracaso escolar no es un destino. Buenos Aires: Colihue, 2008. 
KAPLAN Carina Viviana \& V. ORCE (Orgs.) (2009). Poder, prácticas sociales y proceso civilizador: Los usos de Norbert Elias. Buenos Aires: Noveduc, p. 157-164, 2009.

KAPLAN, Carina Viviana y SARAT, Magda (Orgs.). Educação, Subjetividade e Diversidade: pesquisas no Brasil e na Argentina, Ed. Universidade Estadual de Londrina: Brasil, 2014.

KAPLAN, Carina Viviana y SARAT, Magda (Comp.). Educación y procesos de civilización. Miradas desde la obra de Norbert Elias. Buenos Aires: Editorial de la Facultad de filosofía y Letras. Universidad de Buenos Aires, 2016.

KEJNER, Emilse Malke. Los jóvenes como sujetos de los conflictos sociales de la norpatagonia. Representaciones en la prensa gráfica (1969-1974). Tesis de Maestría en Análisis del discurso. Facultad de Filosofía y Letras. Universidad de Buenos Aires. Argentina, 2011.

KROTSCH, Lucas y GEBARA, Ademir Civilización, fronteras y construcción del Estado Nacional Argentino: Domingo F. Sarmiento. En: Kaplan, C. V. y Sarat, M. (Comp.). Educación y procesos de civilización. Miradas desde la obra de Norbert Elias. Buenos Aires: Editorial de la Facultad de filosofía y Letras. Universidad de Buenos Aires, 2016.

LAHIRE, Bernard. L'invention de l'illettrisme: rhétorique publique, éthique et stigmates. La Découverte: París, 1999.

LANDI, Oscar. Cultura y política en la transición a la democracia. Caracas: Sociedad. Latina. México: FELAFACS, 1984.

LEVI, Giovanni y SCHMITT, Jean Claude Introducción. En: Historia de los jóvenes. Madrid: Taurus, 1996.

LÓPEZ, Rafael y CERDA, Aida Violencia en la televisión mexicana: un análisis del contenido de los treinta programas con mayor audiencia. En: Hiper-textos, v. 2, n. 1, 2001.

MARTÍN CRIADO, Enrique. Mentiras, inconsistencias y ambivalencias. Teoría de la acción y análisis de discurso. En: Revista Internacional de Sociología, v. 72, n. 1, enero/ marzo, p. 115-138, 2014.

MARTINI, Stella. La prensa gráfica argentina: reflexiones sobre la calidad periodística, la información 'socialmente necesaria' y la participación ciudadana en las agendas sobre el delito. En: Suarez Amado, Adriana. Periodismo de calidad: debates y desafíos. Buenos Aires: La Crujìa, 2007.

MARTINI, Stella. Periodismo, noticia y noticiabilidad. Buenos Aires: Norma, 2004.

MÍGUEZ, Daniel y NOEL, Gabriel. Entre el pánico moral y el suceso real: la violencia escolar en la Argentina reciente. Ponencia presentada en el VIII Congreso Argentino de Antropología Social, Salta, septiembre, 2006.

MUCHEMBLED, Robert. Una historia de la violencia. Del final de la Edad Media a la actualidad. Buenos Aires: Paidós, 2010. 
NÚÑEZ, Trinidad. Los profesores vistos por la prensa: de la realidad al mito social. En: Comunicar, v. 12, n. 1, p. 47-54, 1999.

POOLI, João Paulo. Socialización, educación y procesos civilizadores. En: C. V. Kaplan \& V. Orce (Orgs.). Poder, prácticas sociales y proceso civilizador: Los usos de Norbert Elias, p. 157-164. Buenos Aires: Noveduc, 2009.

PUIGGRÓS, Adriana. Sujetos, disciplina y currículum en los orígenes del sistema educativo argentino. Buenos Aires: Galerna, 2006.

QUÉS, María Elena. Medios y política. Imágenes, discursos y sentidos. Buenos Aires: Editorial Universitaria Rioplatense, 2013.

SAEZ, Virginia. Prácticas discursivas de la mediatización de la violencia en espacios escolares. Tesis presentada con el fin de cumplimentar con los requisitos finales para la obtención del título Doctor de la Universidad de Buenos Aires en Educación, no publicada, Facultadde Filosofía y Letras, Universidad de Buenos Aires, Argentina, 2016.

SAEZ Virginia. Una mirada a la investigación sobre medios, violencia y escuela. En: Revista Entramado, v. 11, n. 1, p. 136-155, 2015.

SAINTOUT, Florencia. Los jóvenes argentinos: desde una epistemología de la esperanza. Quilmes: Editorial UNQ, 2013.

SIRVENT María Teresa. El Proceso de Investigación. Investigación y Estadística I. Buenos Aires: Oficina de Publicaciones de la Facultad de Filosofía y Letras (Opfyl), 2003. SWAAN, Abram. Regresión al Servicio del Estado. Reflexiones sobre la Violencia Masiva. En: Subje/Civitas, v. 8, n. 1, p. 1-15, 2011.

TOSSOUNIAN, Cecilia Women's Associations and the Emergence of a Social State: Protection for Mothers and Children (Buenos Aires, 1920-1940), Journal of Latin American Studies, v. 45, n. 2, p. 297-324, 2013.

UNICEF Y FLACSO. Clima, conflicto y violencia en las escuelas. Argentina: FLACSO. Disponible en: <www.unicef.org/argentina/spanish/clima_conflicto_violencia_escuelas. pdf>. 2011.

VAN DIJK, Teun A. Racismo y discurso en América Latina: una introducción. En: Teun A. Van Dijk (coord.). Racismo y discurso en América Latina, p. 21-34. Barcelona: Gedisa Editorial, 2007.

VASILACHIS DE GIALDINO, I. El lenguaje de la violencia en los medios de comunicación. Las otras formas de ser de la violencia y la prensa escrita. Argentina, Consejo Nacional de Investigaciones Científicas y Técnicas (Conicet). Disponible en: <http://biblioteca.secyt.gov.ar>. 2004.

VERÓN, Eliseo. Introducción. En: Construir el acontecimiento. Buenos Aires: Gedisa, 1983. 
WIEVIORKA, Michael. Racismo. Una introducción. Barcelona: Gedisa, 2009.

ZULLO, Julia. Estrategias de la prensa actual: información, publicidad y metadiscurso. En: Raiter A. Representaciones Sociales. Buenos Aires: Eudeba, 2002.

\section{FUENTES CONSULTADAS}

El Día enero 1993-diciembre 2011; Hoy, enero 1993-diciembre 2011, Extra, enero 2002-diciembre 2011, y Diagonales enero 2008-diciembre 2011.

\section{Dados das Autoras}

\section{CARINA VIVIANA KAPLAN}

Doctora en Educación por la UBA y Magíster en Ciencias Sociales y Educación por la FLACSO, Argentina. Posdoctorado en la Universidad Estadual de Rio de Janeiro. Profesora Titular Ordinaria de Sociología de la Educación en el Departamento de Ciencias de la Educación de la Facultad de Humanidades y Ciencias de la Educación de la Universidad Nacional de La Plata y Profesora Adjunta Regular del Departamento de Ciencias de la Educación en la FFyL de la UBA a cargo de las cátedras de Sociología de la Educación y de Teorías Sociológicas. Investigadora Independiente del CONICET. Directora del Programa de Investigación sobre Transformaciones sociales, Subjetividad y Procesos educativos del IICE - UBA. kaplancarina@gmail.com

\section{VIRGINIA SAEZ}

Doctora en Educación por la UBA, Magister en Educación: Pedagogías Críticas y Problemáticas Socioeducativas, Licenciada en Ciencias de la Educación y Profesora en Enseñanza media y superior en Ciencias de la Educación por la Universidad de Buenos Aires (UBA). Becaria postdoctoral del CONICET con sede en el Instituto de Investigaciones en Ciencias de la Educación de la Universidad de Buenos Aires (UBA). Es Integrante del Programa de Investigación sobre Transformaciones Sociales, Subjetividad y Procesos Educativos dirigido por la Dra. Carina V. Kaplan con sede en el Instituto de Investigaciones en Ciencias de la Educación de la Universidad de Buenos Aires (UBA). Se desempeña como docente en la UBA y la Escuela Normal Superior N ${ }^{\circ} .5$ Gral Don Martín Miguel de Güemes.saezvirginia@hotmail.com

Submetido em:25-8-2017

Aceito em: 6-11-2017 